\title{
Eight years of integrated monitoring in Alpine forest ecosystems of Trentino and South Tyrol, Italy
}

\author{
Paolo AMBROSI*, Andrea BERTAGNOLLI, Mauro CONFALONIERI ${ }^{1)}$, Nicola LA PORTA, Flavio MARCHETTI, \\ Giorgio MARESI, Stefano MINERBI ${ }^{2}$, Cristina SALVADORI and Ruggero VALENTINOTTI
}

Unità Operativa Foreste - DRNA Centro Sperimentale, Istituto Agrario di S. Michele a/Adige (IASMA) Via Mach, 1, 38010 S.

Michele a/Adige, Trento, Italy

${ }^{1)}$ Servizio Foreste PAT (Provincia Autonoma di Trento), Via G.B. Trener 3, 38100 Trento, Italy

${ }^{2)}$ Ripartizione Foreste, Provincia Autonoma di Bolzano, Via Brennero 6, 39100 Bolzano, Italy

*e-mail corresponding author: Paolo.Ambrosi@mailismaa.it

\begin{abstract}
After the acute emergency of decline in European woodland at the beginning of 1980's, forest health was the subject of several studies in Trentino and South-Tyrol. Since 1992 investigations focused on an integrated monitoring under the UN-ECE-ICP programme in 4 selected areas, 2 in subalpine Norway spruce woodland (Lavazè Pass and Renon), and 2 in thermophilous Pubescent oak woodland (Pomarolo and Monticolo). The interdisciplinary programme of integrated monitoring aimed to investigate the state of alpine semi-natural forests in relation to air pollution, anthropogenic stresses, climate changes and trophic-energetic balances. Assessment of forest health by means of crown conditions showed very low levels of defoliation and discoloration in the subalpine areas, while in the other ones the same parameters had slightly higher values. Every year and in all the sites the mean percentages values were always in class 0 and class 1, hence indicating no danger. Weather patterns showed the presence of occasional water deficit, albeit general trends were not observed. High level of pollution were never detected while the level of acidity in rainfall has been slightly decreasing in all the investigated plots. Only ozone showed higher values than normal but there was no correlation with any damage. Foliar mineral nutrient contents ranged quite always within the threshold level. Because of the few years of observation and the absence of relevant stress, it is not possible to get any indication about the relationship between the forest health status and the fungi community composition. The presence of some anomalous data and the growing concern on climate change give reason to the importance of a continuous monitoring action acquiring of comparable set of data, in order to get a better understanding of forest ecosystems response to stress and make progress in general ecological knowledge.
\end{abstract}

Key words: integrated monitoring, forest health, air pollution, meteorological stress

\section{INTRODUCTION}

In the last 20 years investigations on forest decline were carried out all over Europe, showing that this phenomenon may be an indication of modifications due to pollution, human impact, climate changes and land use or natural events connected to ecosystem evolution (Innes 1993). It is now generally accepted that all these factors can produce change in forest conditions acting as a mixture of stress agents able to enhance each other (Van Leeuwen et al. 2000). In this context the integrated monitoring proved to be a good tool to understand the effects of several factors and the relationships between them, undertaking thorough investigations involving wide range of expertise in different specific field.

This is why, since 1992, 4 sites, representative of Trentino - South Tyrol (T.S.T.) woodlands, have been chosen for the intensive and integrated monitoring of forest ecosystem, 2 in subalpine Norway spruce woodland and 2 in thermophilous Pubescent oak woodland. Permanent plots were set up, equipped with specific instruments and joined to the European monitoring network for the assessment of forest health. The research protocols followed the guidelines issued by the UN ECE Convention on Long-Range Transboundary of Air Pollution, and complied with the methodologies adopted in the following projects:

- ICP- IM International Cooperative Program on Forest and Integrated Monitoring;

- CONECOFOR Controllo Ecosistemi Forestali (Norway spruce stands only) (Allavena et al. 1999).

This strong interest in forest health is well justified by the importance of woodslands that in T.S.T., cover more than $50 \%$ of land, characterising economy, landscape and culture. Stress factors can influence the choices of a naturalist management aiming to enhance all the functions of woodland, but saving its ecological specificity and resilience. Till now several research were carried out on different aspects of forest decline in T.S.T. - even in absence of worrying symptoms (Ambrosi \& Minerbi 2001; AA. VV. 1991a; AA. VV. 1992) - but data and analysis was always performed on single parameters (AA. VV. 1991b).

Being the first attempt to assess the detailed relationships between forest health conditions and environmental stress, this paper reports and discuss data collected in the first eight years of monitoring (1992-1999)

Paper partly prepared within the CONECOFOR programme, by the contract with the Ministry for Agriculture and Forestry Policy - National Forest Service, Italy. CONECOFOR is part of the Pan-European Level II Intensive Monitoring of Forest Ecosystem and is co-sponsored by the European Commission. 
for the following sub-programs: meteorology, air chemistry, precipitation chemistry, foliage chemistry, forest damage, mycological analysis.

\section{METHODS}

\subsection{Monitoring sites description}

Two plots are located in Trentino, Pomarolo (IT04) and Lavazè Pass (IT03), and 2 in South Tyrol, Monticolo (IT02) and Renon (IT01). IT04 and IT02 are representative of deciduous forest (Quercetum pubescentis) at low altitude (680 and $560 \mathrm{~m}$ a.s.l. respectively). They are dominated by Quercus pubescens, Quercus robur, Fraxinus ornus and Ostrya carpinifolia, with secondary presence of Castanea sativa, Pinus silvestris, Larix decidua and Picea abies. The climate is mild continental with sub-mediterranean influences. Mean annual temperature is around $11^{\circ} \mathrm{C}$ for both the sites. Mean annual precipitation is $800 \mathrm{~mm}$ in IT02 and $1150 \mathrm{~mm}$ in IT04. IT02 stand grows on an superficial acid brown soil, above quartz porphirit rocks, while IT04 is located on cambisol, in a limestone area.

IT01 (1750 $\mathrm{m}$ a.s.1.) and IT03 (1780 m a.s.1.) are both representative of the association Picetum subalpinum. These woods are formed mainly by Picea abies with presence of Pinus cembra and Larix decidua. The climate is alpine-continental and the annual mean temperature is $4{ }^{\circ} \mathrm{C}$ in both the localities, while the mean annual precipitation are $1100 \mathrm{~mm}$ for IT03 and $970 \mathrm{~mm}$ for IT01. The stands grow on podsolic soil above quarz porphirit rocks. The following subprograms of the cited projects (ICP - IM and CONECOFOR) are carried out in the sites.

\subsection{Meteorology}

In all the sites a meteorological automatic station, placed in an open area as indicated by the WMO guidelines (WMO 1998). The following parameters are recorded: precipitation, temperature of the air, relative humidity, global radiation. The readings for most of these variables are hourly. In this paper, only precipitation and temperature data were examined.

The climatological pattern in T.S.T., data of thirty years (1970-1999) of both temperatures and rainfall were examined in general terms, calculating water deficit with Thornthwaite for the stations of S. Michele a/Adige, $210 \mathrm{~m}$ a.s.l. (Istituto Agrario S. Michele a/Adige IASMA), and Redagno, $1562 \mathrm{~m}$ a.s.l. (Hydrografic Service of Autonomous Province of Bolzano), representative respectively of valley and quote conditions. Data were statistically analysed.

Indications on seasonal precipitation in T.S.T. were obtained from data recorded by the SPARTAC climatological stations network managed by IASMA (Eccel \& Toller 1996).

\subsection{Air chemistry}

Measurements on air pollution are carried out only at IT01 site; since 1990, this area is equipped with automatic specific sensors continuously recording air composition; are the principal parameters recorded are $\mathrm{NO}_{\mathrm{x}}$ (MICROS, AC31M Environment), $\mathrm{SO}_{2}$ (MICROS, Monitor Labs 8850S), O 3 (MICROS, Dasibi 1108). Since 1999 passive samplers for ozone and nitrogen dioxide (dosimeter) are employed in the IT03 area.

\subsection{Precipitation chemistry}

In the 4 sites precipitation were sampled weekly. While IT01 and IT02 have both bulk and wet equipment and data were collected for 8 years (1992-1999), IT03 and IT0 4 have only bulk samples with 4 years of data (1996-1999). Devices for sampling throughfall, stemflow and soil water were also placed in the monitoring sites. Samples were analysed for the main ions $\left(\mathrm{H}^{+}, \mathrm{Na}^{+}\right.$, $\left.\mathrm{K}^{+}, \mathrm{Ca}^{2+}, \mathrm{Mg}^{2+}, \mathrm{NH}_{4}{ }^{+}, \mathrm{SO}_{4}{ }^{2-}, \mathrm{NO}_{3}{ }^{-}, \mathrm{Cl}^{-}\right)$accordingly with the standardised methods (APHA, AWWA, WEF 1992).

\subsection{Foliage chemistry}

Leaf samples were collected since 1995 every two years at the end of vegetative season. Five individuals of dominant species (Picea abies and Quercus pubescens) were sampled in each site. Analysis of 6 macronutrients (S, N, P, Ca, Mg, K, Na) were performed according to AOAC International (1970). Data from 3 surveys, carried out in 1995-97-99, and of 2 sites (IT03-IT04) are presented.

\subsection{Forest damage}

On a sample of 30 trees in each study site, chosen between the dominant ones, defoliation (\%) and discoloration (\%) were evaluated each year employing the methodology adopted by EU regulation 1696/87. Visual assessment was carried out in July-August always by the same operator.

\subsection{Mycological analysis}

In each site three plots, for a total of $675 \mathrm{~m}^{2}$, were delimited and fenced. Qualitative and quantitative data were collected weekly for about nine months (from April to December), starting since 1994 until 1999. Number, frequency and biomass of the macromycetes species were assessed collecting the fruiting bodies.

\section{RESULTS}

\subsection{Meteorology}

The main meteorological data collected during the 8 years in the 4 localities are summarised in figure 1 . Climatic characteristics of the sites are strictly related to their geographic position between the prealpine region and the alpine continental region. It was recorded a summer solstitial type of rainfall distribution (maximum value in summer and minimum value in winter), even if Mediterranean influences can be observed for IT04 and specially IT02 (transition to subequinotial type). The driest periods were mainly in February - March. The 

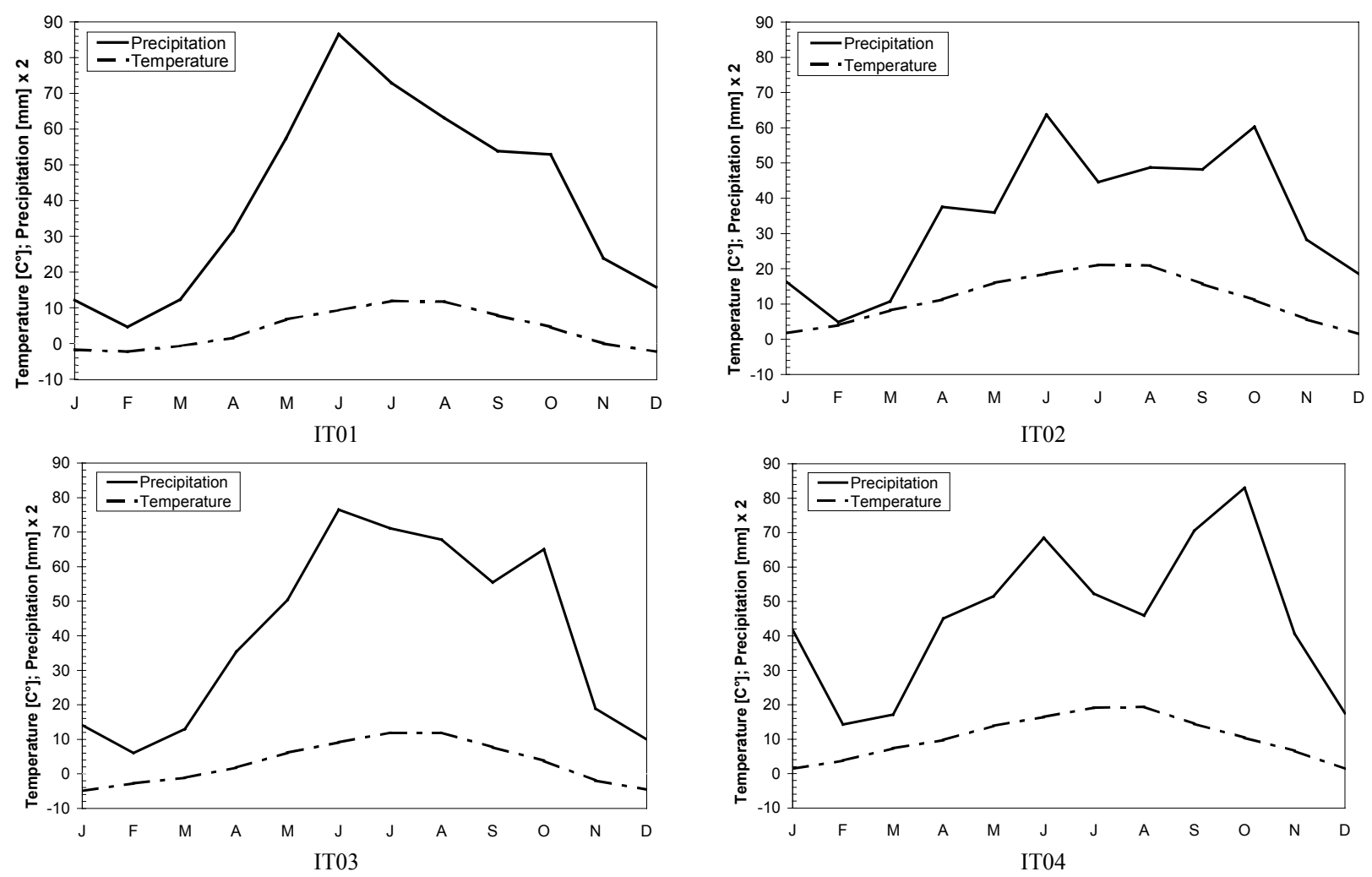

Fig. 1. Gaussen Diagram for the four monitoring sites (monthly means 1992-1999).

months of water deficit were calculated using Gaussen method for IT02: from 1992 to 1999, values were 1, 3, $1,3,2,4,2,1$ respectively.

Temperature and water deficit data are reported in figure 2. The temperature recorded in both stations are slightly higher in the last 10 years than in the 80 's, even if a significant linear regression was obtained only for Redagno. In the context of all the three decades examined rainfalls and water deficit are fluctuating and no apparent trend can be detected.

Seasonal precipitation are shown in figure 3. At regional level on the basis of SPARTAC network stations, 1995 and 1997 were dryer years in the monitoring period.

\subsection{Air chemistry}

All the parameters investigated in IT01 confirm the trend showed in the previous analysis (Ambrosi et al. 1997) with no great difference in the annual peaks (Fig. 4). Since 1997 a slight decrease in sulphur dioxide and ozone was observed, while nitrogen dioxide seem to remain constant. Ozone summer concentration in the period 1997-1999 reached, on average, $93 \mu \mathrm{g} \mathrm{m}^{-3}$; previous measurement showed a mean of $104 \mu \mathrm{g} \mathrm{m}^{-3}$ (19921996). Annual maxima measured in the period 19921996 varied between 210 and $242 \mu \mathrm{g} \mathrm{m}^{-3}$ while in the period 1997-1999 varied between 188 and $214 \mu \mathrm{g} \mathrm{m}^{-3}$. From April to September the values recorded greatly exceeded the critical level (AOT40 $=10,000 \mathrm{ppb}$ ), approx. 25,000 ppb were recorded. Years 1997-1999 showed however a appreciable decrease $(-19 \%)$ with respect to the years 1992-1996. In the 1999 at IT03 the calculated mean was $92 \mu \mathrm{g}\left[\mathrm{O}_{3}\right] \mathrm{m}^{-3}$ (values courtesy of Istituto di Ricerche Ambiente Italia - CONECOFOR), albeit with a different analyser was employed.

\subsection{Precipitation chemistry}

Total annual precipitation in the 4 sites varies between $800 \mathrm{~mm}$ to $1100 \mathrm{~mm}$ and is moderately acid (Tab. 1a). High values of $\mathrm{pH}$ (annual maxima) are related to relatively frequent episodes of transport of alkaline dust from the Sahara (Tait \& Thaler 2000) while the minimum values are rare and linked with weak rainfall after a long period of no precipitation: figures lower than $\mathrm{pH}=4$ in more than $8 / 10$ of the events, are associated with rainfall $<2 \mathrm{~mm}$. All the sites are characterised by median values in a short range. Wet devices at IT01 and IT02 shows that the dust present in the lower strata of atmosphere reduces roughly about $10-15 \%$ the frequencies of samples with acid precipitation.

The free acidity was decreasing in the IT01 and IT04; the range of $\mathrm{pH}$ variation recorded in the two sites appears similar during the years and discrepancies were probably related to seasonal variations in the rainfall regime, bearing in mind that IT01 is located in the middle of Alps whereas IT04 is located in the Prealps. 


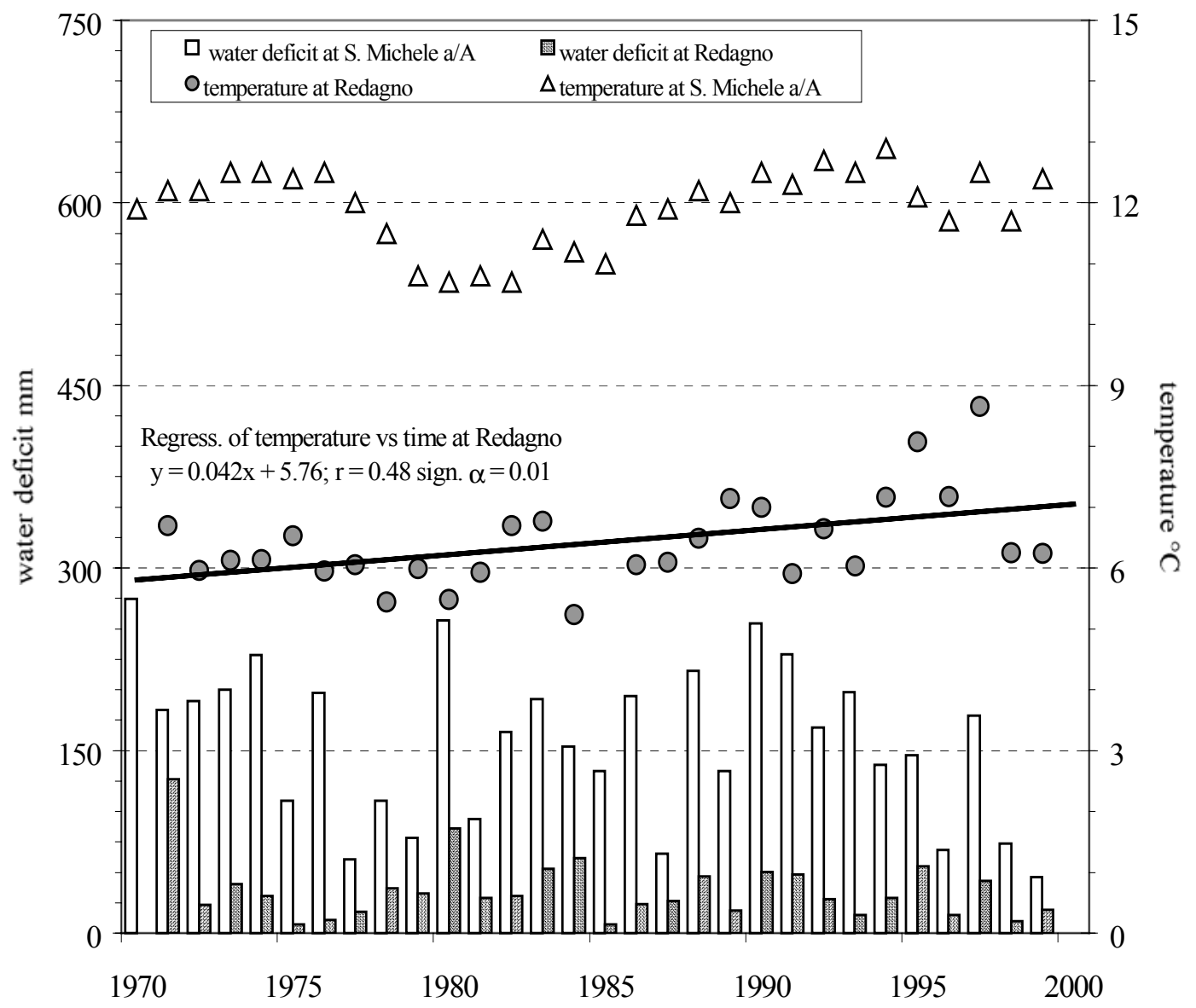

Fig. 2. Thirty years trend of temperature and water deficit (mod. Thornthwaite) at S. Michele a/Adige (210 m a.s.1.) and Redagno (1562 m a.s.l.).

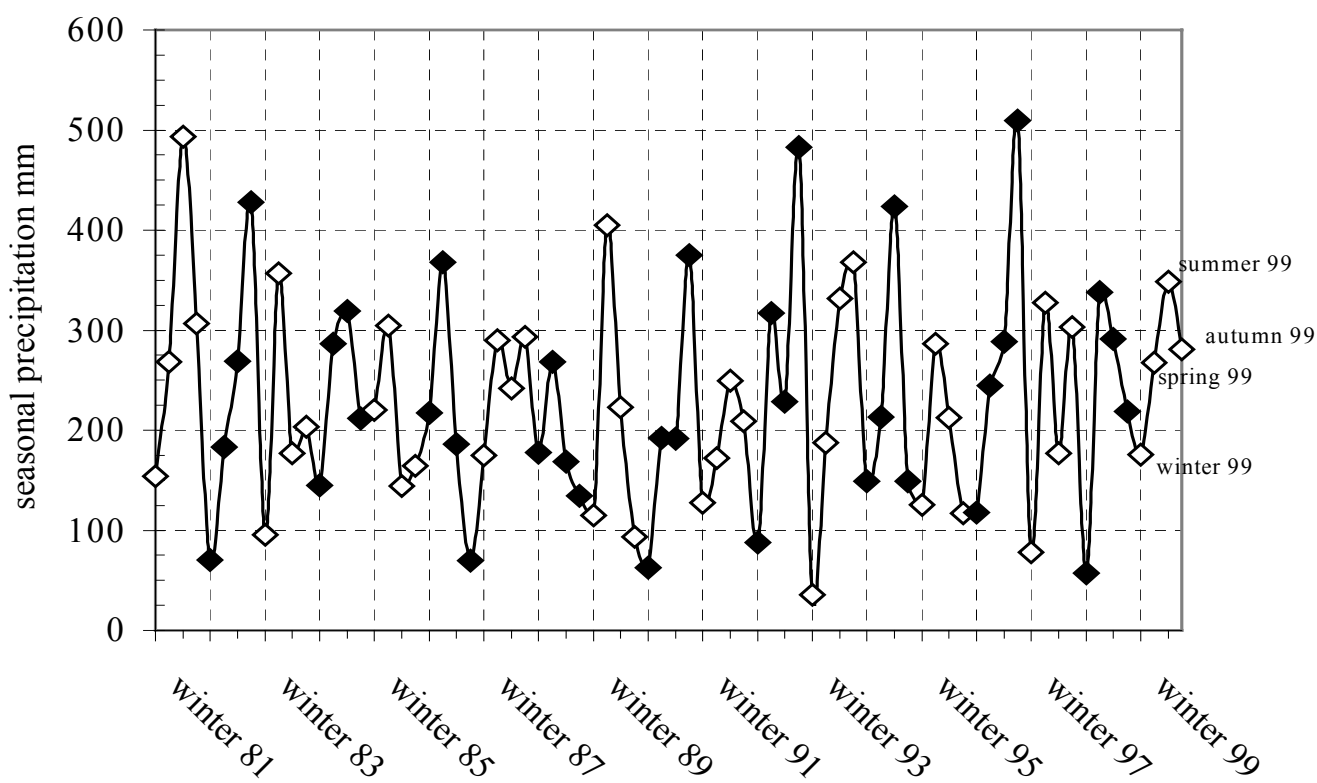

Fig. 3. Trend of seasonal mean of precipitation (SPARTAC meteorological network - IASMA). 


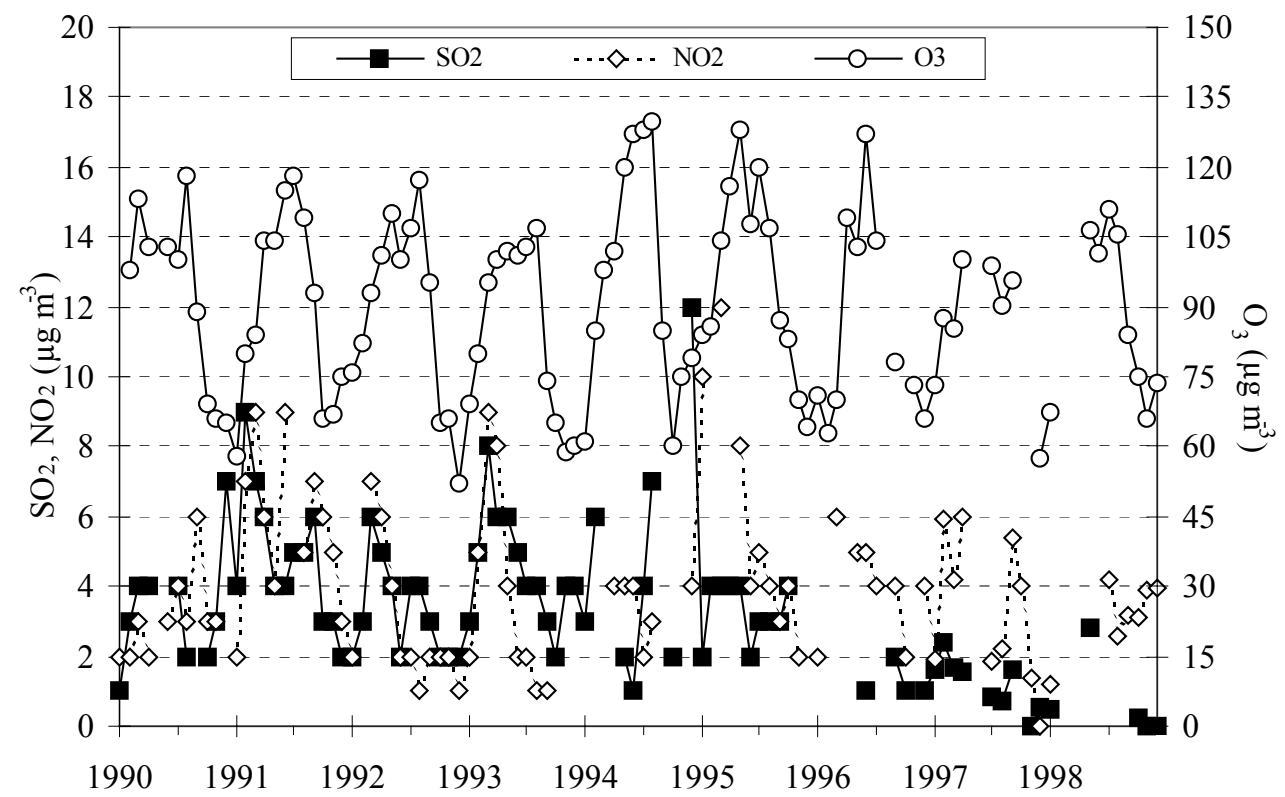

Fig. 4. Monthly means for $\mathrm{SO}_{2}, \mathrm{NO}_{2}, \mathrm{O}_{3}$ at IT01 (from Minach 1996; modified).

Tab. 1a. Statistical parameters of $\mathrm{pH}$ in open field precipitation. * wet only.

\begin{tabular}{lccccccccc}
\hline Site & period & $\mathrm{N}$ & $\min$ & I quartile & median & III quartile & $\max$ & $\mathrm{pH}<5.6$ & $\mathrm{pH}<4$ \\
\hline IT01 & $1992-99$ & 315 & 3.4 & 4.9 & 5.3 & 5.8 & 7.8 & $68 \%$ & $2 \%$ \\
IT02 & $1992-99$ & 285 & 3.7 & 4.9 & 5.3 & 6.1 & 7.3 & $56 \%$ & $1 \%$ \\
IT01* & $1992-99$ & 309 & 4.0 & 4.9 & 5.2 & 5.5 & 7.2 & $77 \%$ & $0 \%$ \\
IT02* & $1992-99$ & 263 & 3.8 & 4.7 & 5.1 & 5.7 & 7.3 & $72 \%$ & $1 \%$ \\
IT03 & $1996-99$ & 89 & 3.8 & 4.7 & 5.1 & 5.8 & 8.6 & $63 \%$ & $2 \%$ \\
IT04 & $1996-99$ & 110 & 4.2 & 5.0 & 5.5 & 5.9 & 6.9 & $56 \%$ & $0 \%$ \\
\hline
\end{tabular}

Tab. 1b. Statistical parameters of $\mathrm{pH}$ in throughfall precipitation.

\begin{tabular}{lccccccccc}
\hline Site & period & $\mathrm{N}$ & $\min$ & I quartile & median & III quartile & $\max$ & $\mathrm{pH}<5,6$ & $\mathrm{pH}<4$ \\
\hline IT01 & $1998-99$ & 80 & 4.2 & 4.9 & 5.3 & 5.7 & 6.9 & $71 \%$ & $0 \%$ \\
IT02 & $1998-99$ & 67 & 4.7 & 5.6 & 6.0 & 6.3 & 8.6 & $21 \%$ & $0 \%$ \\
IT03 & $1996-99$ & 83 & 3.6 & 4.7 & 5.0 & 5.6 & 7.3 & $75 \%$ & $1 \%$ \\
IT04 & $1996-99$ & 125 & 4.5 & 5.5 & 5.8 & 6.1 & 7.3 & $26 \%$ & $0 \%$ \\
\hline
\end{tabular}

The other two sites show a similar trend but the figures are less consistent. The linear interpolation of the monthly averaged values of $\mathrm{pH}$ at IT01 (significant at $\alpha=0.05$ ) shows a regular tendency in the reduction of free acidity (Fig. 5). IT04 shows the most consistent ion input in comparison to the other sites even if the ratio of anions and cations appear similar in all the sites (Fig. 6). IT04 is clearly influenced by the proximity to the urbanised areas of Northern Italy (Padana Plan); detailed results on fluxes in the 4 areas and comments on deposition are published elsewhere (Marchetti et al. 2002).

The contribution of acidic ions of anthropogenic origin, $\mathrm{NO}_{3}{ }^{-}$and $\mathrm{SO}_{4}{ }^{2}$, accumulated on leaves and needles through dry deposition is relatively modest and compensated by increment of cations released from foliar apparatus, so that the throughfall precipitation $\mathrm{pH}$ results slightly acid only in the coniferous areas (IT01 and
IT03) and it is comparable, on average, with those reached in open field mode (Tab. 1b). Annual mean deposition (1996-1999) of net acidity is - 11,5 mmol $\mathrm{m}^{-2} \mathrm{y}^{-1}$ and $-10,5 \mathrm{mmol} \mathrm{m} \mathrm{m}^{-2}$ at IT01 and IT02 respectively and potential acidity is $53 \mathrm{mmol} \mathrm{m}^{-2} \mathrm{y}^{-1}$ and $39 \mathrm{mmol} \mathrm{m}^{-2} \mathrm{y}^{-1}$ (Tait, personal communication).

\subsection{Foliage chemistry}

In Norway spruce needles (IT03) the quantity of most elements was in the optimal range as reported for the same species (threshold values of Expert Panel on Foliar Analyses - Biino \& Tazzi 1998), except for potassium in 1997 (11.5 vs $\left.9.0 \mathrm{mg} \mathrm{g}^{-1}\right)$ and sulphur in 1995 (0.9 vs $1.1 \mathrm{mg} \mathrm{g}^{-1}$ ) (Fig. 7). In Pubescent oak leaves (IT04) only calcium and magnesium presented higher values than their upper thresholds $\left(8.0 \mathrm{mg} \mathrm{g}^{-1}\right.$ and 1.5 $\mathrm{mg} \mathrm{g}^{-1}$ respectively) in all the sampling years. 


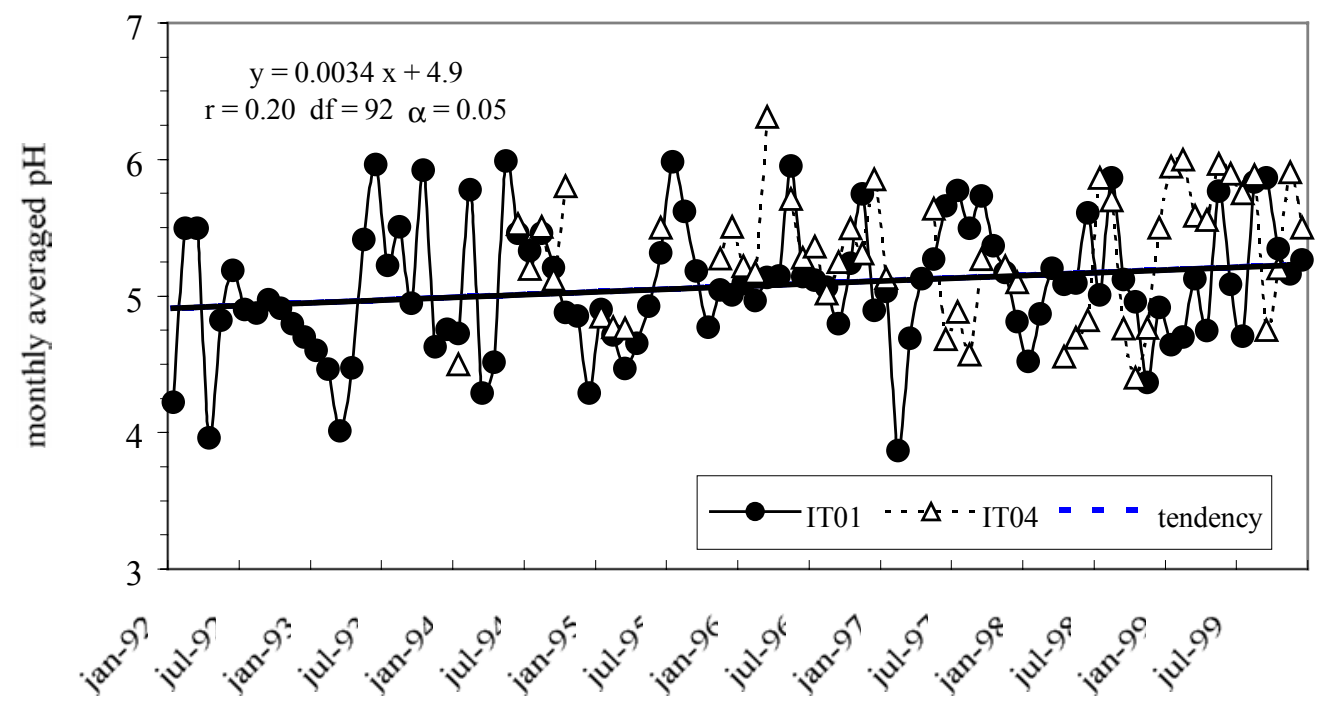

Fig. 5. pH trend of samples collected in open field.

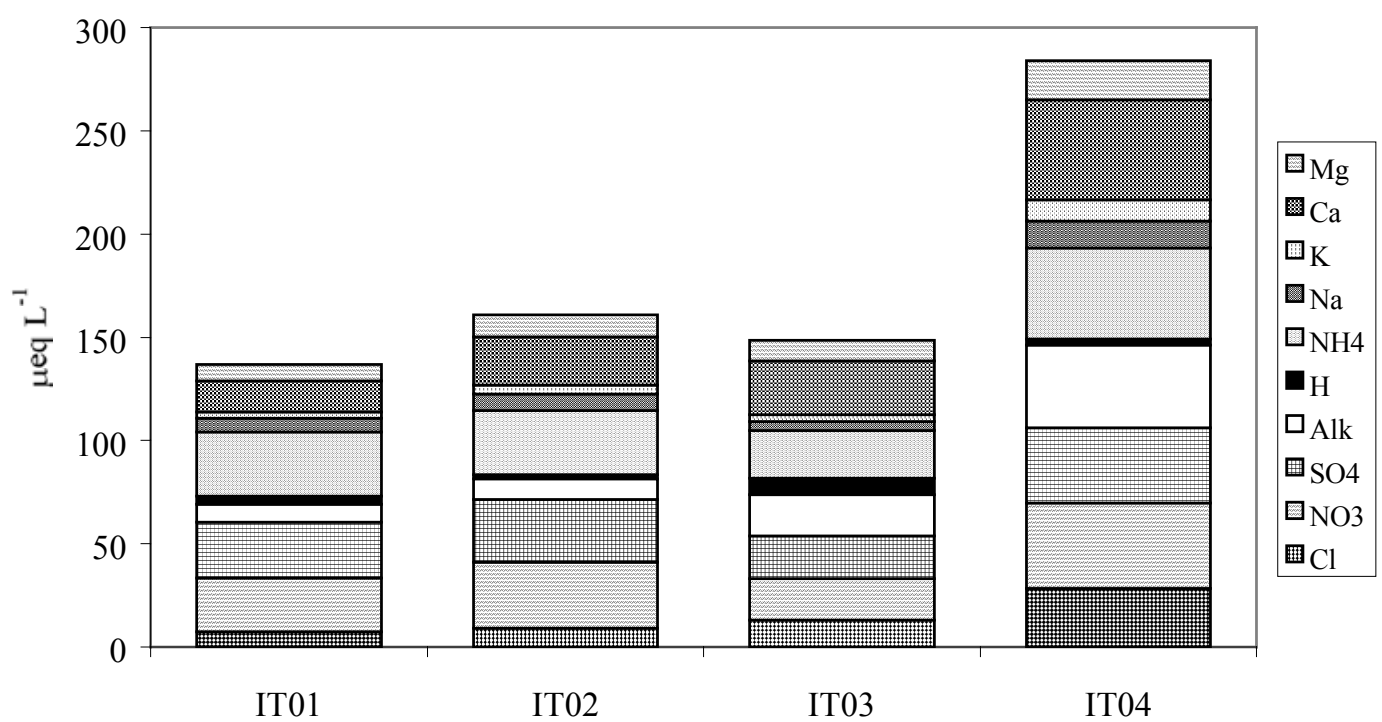

Fig. 6. Average ion concentration of the open field samples (median 1996-99).
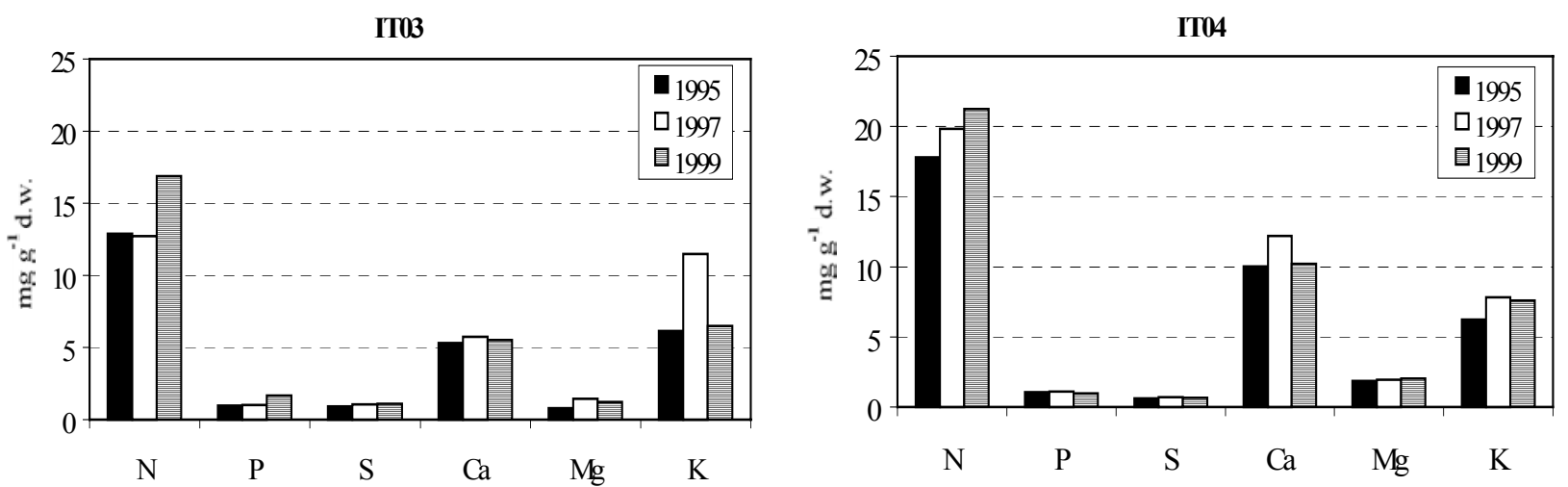

Fig. 7. Mineral nutrient contents in Norway spruce needles (IT03) and Pubescent oak leaves (IT04) at the end of vegetative season $(\mathrm{n}=5)$. 
Tab. 2. Nutrient ratios in Norway spruce needles at IT03 and in Pubescent oak leaves at IT04 $(n=5)$. Normal range is according to Biino \& Tazzi 1999.

\begin{tabular}{lcccccccc}
\hline & $\mathrm{S} / \mathrm{N}$ & $\mathrm{N} / \mathrm{P}$ & $\mathrm{N} / \mathrm{K}$ & $\mathrm{N} / \mathrm{Ca}$ & $\mathrm{N} / \mathrm{Mg}$ & $\mathrm{K} / \mathrm{Ca}$ & $\mathrm{K} / \mathrm{Mg}$ & $\mathrm{Ca} / \mathrm{Mg}$ \\
\hline IT03 & & & & & & & & \\
1995 & 0.1 & 13.5 & 2.1 & 2.4 & 16.5 & 1.2 & 7.8 & 6.7 \\
1997 & 0.1 & 12.8 & 1.1 & 2.2 & 8.9 & 2.0 & 8.0 & 4.0 \\
1999 & 0.1 & 10.1 & 2.6 & 3.1 & 13.9 & 1.2 & 5.3 & 4.5 \\
Normal range & $0.1-0.2$ & $6.0-17.0$ & $1.3-4.9$ & $2.0-11.3$ & $8.0-28.3$ & $0.6-6.0$ & $2.3-15.0$ & $1.0-10.0$ \\
& & & & & & & & \\
IT04 & & & & & & & & \\
1995 & 0.0 & 16.8 & 2.9 & 1.8 & 9.7 & 0.6 & 3.4 & 5.5 \\
1997 & 0.0 & 18.0 & 2.5 & 1.6 & 10.2 & 0.6 & 4.0 & 6.3 \\
1999 & 0.0 & 21.8 & 2.8 & 2.1 & 10.5 & 0.7 & 3.8 & 5.0 \\
Normal range & n.d. & $8.3-25.0$ & $1.5-5.0$ & $1.9-8.3$ & $6.0-25.0$ & $0.6-3.3$ & $2.0-10.0$ & $1.2-8.0$ \\
\hline
\end{tabular}

In both IT03 and IT04, nitrogen concentrations increased during time, but the values remained in the normal range for the 2 species (Picea abies: 12.0-17.0 $\mathrm{mg} \mathrm{g}^{-1}$ - Quercus sp.: 15.0-25.0 $\mathrm{mg} \mathrm{g}^{-1}$ according to Biino \& Tazzi 1998). The N content at IT04 measured during all the period (1995-99) did not show significant changes according to one tail $\mathrm{t}$ test $(\alpha=0.01)$. At IT03, instead, the nitrogen concentration in 1999 was significantly $(\alpha=0.01)$ higher than the previous ones.

Considering that the absolute concentration of the nutrients is often insufficient to evaluate the nutritional status of a tree, the relationships between elements were also examined. Most of the nutrient ratios fall in the normal range (Tab. 2): the only exceptions being represented by the $\mathrm{N}: \mathrm{K}$ ratio for IT03 and the $\mathrm{N}: \mathrm{Ca}$ ratio for IT04 which are slightly lower.

\subsection{Forest damage}

Defoliation and discoloration revealed no clear trends in all sites (Fig. 8). The mean defoliation percentages were always below $22 \%$ and mainly below $18 \%$ (91\% of the data), remaining lower than the threshold value of $25 \%$ : the stands are considered "damaged" when defoliation is above $25 \%$ (Bussotti \& Ferretti 1998). Mean discoloration values never reached 10 $\%$, remaining usually below $8 \%$ (97\% of the data). The range of the mean values variation is lower than $5 \%$ for both the indices, except mean defoliation at IT02 $(12.3 \%)$ and IT04 (6.5\%) and mean discoloration at IT02 $(6.6 \%)$. Even if the mean values of the two parameters showed a very small variation, the $40 \%$ of the examined trees showed changes (both damage and recovery) in defoliation higher than $10 \%$ during the years (20\% of the trees for discoloration). There were several cases where the crown condition considerably improved (from $90 \%$ to $0 \%$ of defoliation), especially if the damage was related to the presence of phytophagous. Only two cases of irreversible evolution occurred due to the action of abiotic (lightning on Picea abies at IT03) and biotic factors (disease on Castanea sativa at IT02). It was relatively easy to find a common pattern in the trends in crown condition between IT01 and IT03, while IT02 showed a anomalous behaviour if compared to IT04. As a matter of fact, the highest crown defoliation and yellowing were in IT02. Considering that deterioration of tree condition is stressed by an increase of the number of "damaged" trees, the annual transition frequency towards upper or lower classes of defoliation has been also determined (Fig. 9). Evidence of damage was observed in 1994, 1995, 1997 and 1998 in comparison to the previous years. The trees showed strong capacity of recovering in the years 1996 and 1999, which followed the driest ones of the investigated period (1995 and 1997-98).

\subsection{Mycological analysis}

All the species of macromycetes were divided in 2 big groups according to their ecological value: saprothroph and mycorrhiza. Biomass of mycorrhizal fungi were always higher than the saprotroph one (Fig. 10). For the first mean values varied among localities and years between $62 \%$ and $84 \%$ of the total fungal biomass. The only exception was represented, in 1995, by the mean values observed in IT02 and IT04 where mycorrhizal fungi reached, respectively, only $20 \%$ and $32 \%$ of the total biomass.

The range of the total mycetes biomass, including both saprotroph and mycorrhiza, ranged between 1117 $\mathrm{g} / 1000 \mathrm{~m}^{-2} \mathrm{y}^{-1}$ in IT03 and $2369 \mathrm{~g} / 1000 \mathrm{~m}^{-2} \mathrm{y}^{-1}$ in IT04.

The localities were ranked for the variation of the biomass weight coefficient along years in the following increasing order: IT03, IT01, IT02 and IT04. The variations among years for the same locality did not show a consistent trend between the two ecological groups, saprotroph and mycorrhiza (data not shown).

One of the major factors that play an important role on the biomass differences among localities is the length of the vegetative season, and the different structure of the vegetation components (flora), both herbaceous and shrub, which appears to be much more complex in the termophilic localities, IT04 and IT02, than in the subalpine ones IT03 and IT01 (Minerbi et al. 1996). 



Fig. 8. Mean percentage values of defoliation and discoloration in the four plots through the years 1992 to $1999(\mathrm{n}=30)$.

IT02

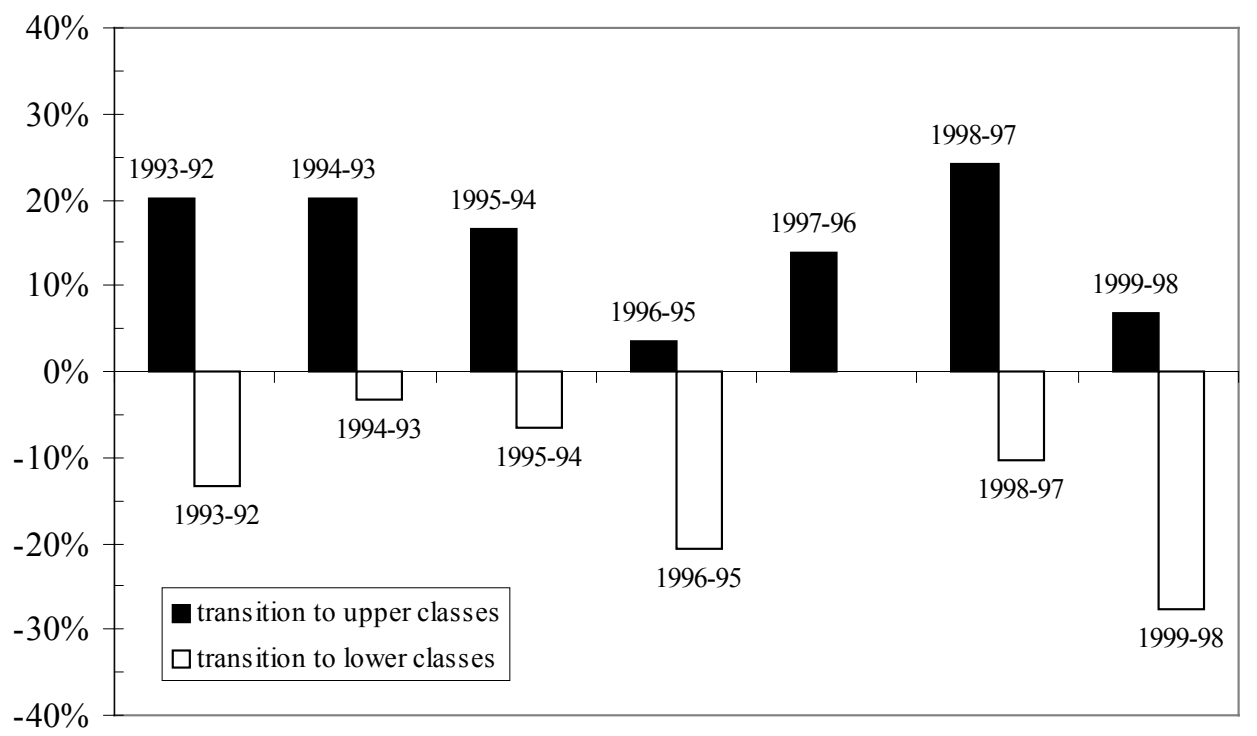

Fig. 9. Annual transition (\%) of trees in different defoliation classes at IT02. (Class $1=0-10 \%$; Class $2=10-25 \%$; Class $3=25-60 \%$; Class $4>60 \%$ ).

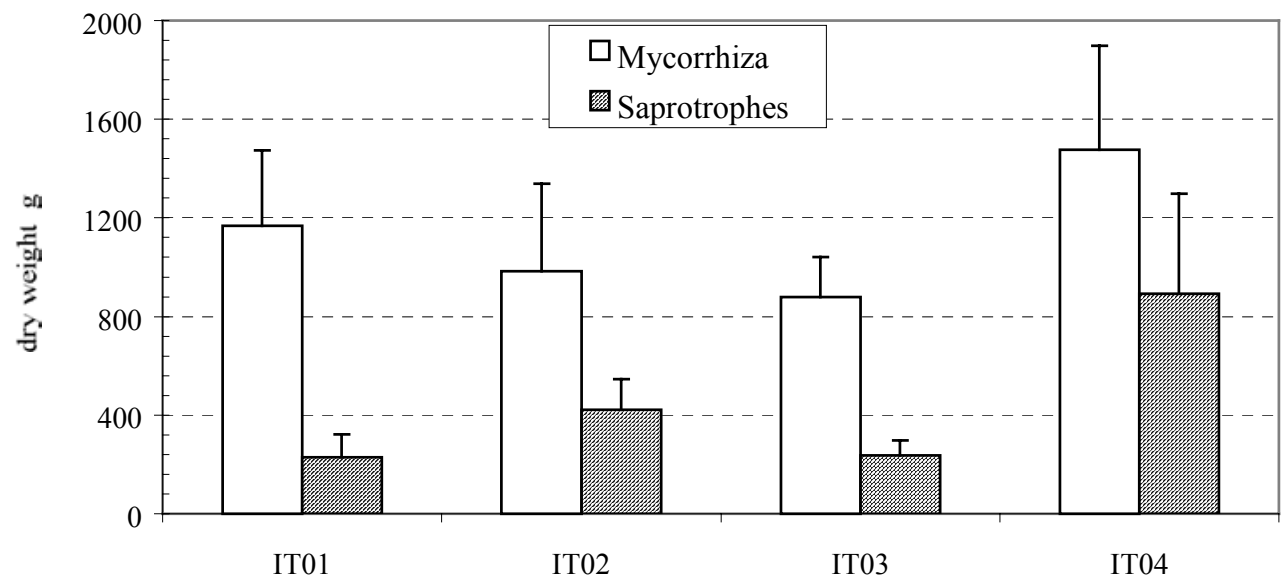

Fig. 10. Mean $(n=6)$ biomass of fungal mycorrhiza and saprotrophes fruit bodies (1994-99). 
As a consequence of these factors, data show that the total fungal biomass of both mycorrhizae and saprotrophes (Fig. 10) are higher in the thermophilic localities, IT04 (2369 g) and IT02 (1405 g), than in the subalpine ones IT03 (1117 g) and IT01 (1396 g).

This result is not comparable for the parameter "number of species". IT04 shows the highest value with 385 species. Surprisingly IT02 with 194 species score the minimum value among all the 4 localities. There is no clear explanation for this. Further analysis may indicate this bias is merely due to few genera very rich in number of species.

The range of total fungal biomass growing on 1000 $\mathrm{m}^{2}$ varies in a regular fashion from a minimum of $309 \mathrm{~g}$ $\mathrm{y}^{-1}$ to a maximum around $3966 \mathrm{~g} \mathrm{y}^{-1}$ per area. IT04 in 1998 is an exception and it is totally out of its ordinary range: in that year the biomass reached in IT04 $8974 \mathrm{~g}$. This peculiar event was caused by the large production of few species, over 300 ones collected in total, among which Armillaria spp., took advantage of particularly favourable seasonal conditions (data not shown).

The total number of species collected along the 6 years in each locality can be considered a preliminary index of bio-diversity. It can be used to rank the localities as bio-diversity potential. The results obtained in total number of species are the following: IT04, 385; IT01, 284; IT03, 210 and IT02, 194.

\section{DISCUSSION AND CONCLUSIONS}

Evaluation of forest health by means of crown conditions showed very low levels of defoliation and discoloration in the 2 subalpine areas, while in the other ones, representative of thermophilic woods, the same parameters had slightly higher values. The worse situation observed at IT02 can be related to the higher sensitivity of this wood, growing at the edge of its natural ecological distribution, to several stresses. Here the effects on forest vegetation of climatic and pedological adverse conditions can be strongly enhanced.

Anyway, in all the observation years and for all the sites the mean percentages always were included in the class 0 and class 1 as defined by the international protocol (Schröter \& Aldinger 1985; Innes 1993). For both these classes there is no danger for the trees. Data appears very reliable because the surveys were carried out by the same operators, that received appropriate training with inter-calibration exercises. This prevents possible bias noted by most of the criticisms on the evaluation methodologies which at European level produced data with limited comparability (De Vries et al. 2000).

The general good conditions suggest the absence of environmental stress, at least in the limited observation period. The results of each subprogram confirm and enhance this general statement.

8 years of meteorological data for each site do not allow a climatic analysis but show clearly as weather patterns are in the natural range for the ecological re- quirement of the dominant species (Bernetti 1995): Picea abies in IT01 and IT03 and Q. pubescens in IT02 and IT04.

Analysis of climatic data for the meteorological stations of S. Michele a/Adige and Redagno and for the SPARTAC network suggest for T.S.T. the absence of evident trend with the only exception of the slight but significant increase $\left(0,05{ }^{\circ} \mathrm{C} \mathrm{y}^{-1}\right)$ in temperature values for the high altitude station. Water deficit were recorded in the observation years and in the previous period both in the monitored sites than on regional level. This stress appears to have no clear trend but seems to happen occasionally. A relation between the observed water deficit period and the increase of defoliation level can be proved only for IT02, where probably the soil condition enhance the effect on the trees. A better understanding of the relationship between meteorological stress and plant physiology is one of the target of the future work. Even if no evidence of global climatic change can be detected by the few meteorological data examined in this work, other analysis have recently suggested also for T.S.T. growing concerns such as the reduction in glaciers surfaces (Zanon 1999).

The evaluation of air quality reveals that $\left[\mathrm{SO}_{2}\right]$ decreased, like in other European monitoring plots (Michaelis 1997), as a consequence of the general reduction of sulphur emission, since '80 (Doytchinov 1996). Accurate and extensive investigation on deposition in forested areas were made since 1985 at IT01. Ozone concentrations reached the level $\left(80 \mu \mathrm{g} \mathrm{m}^{-3}\right)$ considered toxic for sensitive vegetation both at IT01 and IT03, but, despite this fact, the observation on crown condition did not reveal serious damages, as reported in the specific chapter. The trend of the main chemical variables related to atmospheric deposition $\left(\mathrm{H}^{+}, \mathrm{NO}_{3}{ }^{-}, \mathrm{NH}_{4}{ }^{+}\right.$, $\mathrm{SO}_{4}{ }^{\circ}$ ) were recently published by Tait \& Thaler (2000); they report a clear decrease of the total acidifying level in the atmospheric wet deposition examined in the period 1985-1999.

The depositions appear moderately alkaline and according to the classification of North-eastern alpine zones, the parameter of potential acidity can be defined acid deposition sensitive areas (class $=4$ ) (Bonanni et al. 1998). The IT03 area belongs to a more sensitive class (class $=5$ ) and for this reason further investigations, particularly on nitrogen role, appear necessary.

In the foliar chemical composition, the observed increase of $\mathrm{N}$ contents and the 2 ratios (especially $\mathrm{N}: \mathrm{K}$ ) that are out of the normal range, need to be confirmed by the next biennial analysis (2001-2003). The time of investigation (5 years) is still too short to detect the effects of environmental changes on tree nutrition. Because of the relevant role of nutrition in several types of forest decline (Innes 1993), it will be important to increase the knowledge on the effects of geochemical and climatic aspects, which are the main factors affecting the nutritional status (Schleppi et al. 2000). 
Mycological analysis suggest some preliminary observation on bio-diversity as a tool to study forest health condition. Even if macromycetes represent a limited component to evaluate the complexity of the examined ecosystems, some important indication about difference between the thermophylus broadleaves woods and the subalpine Picea woods can be underlined, even if this was possible only for total biomass and not for number of species. This fact confirms as macromycetes diversity is strictly related to site condition and especially vegetation composition (La Porta et al. 2000). Because of the few years of observation and the absence of real stress, both climatic and anthropogenic, it is not possible to argue any indication about relationship between forest health status and fungi community composition. There are so far very few data on the role of single fungi species on roots functionality and on species succession in stands ageing; more research work is desirable on this subject. However, mycological data collection is going to continue in order to have a larger chronological database. The research on bio-diversity data should be extended to other ecosystem components such as insects and micromammals communities.

Considering that the data so far acquired prove that in regional there is low level of crown damages and low level of deposition in comparison with other neighbouring areas, we agree with Kandler \& Innes (1995) in their wide recognition on "Waldsterben" concept, in which they suggested that for many areas the role of air pollution is modest if compared to species-specific or site-specific factors that play a much relevant role in forest decline.

However some anomalous data such as ozone concentration and the growing concern on climate change justify the importance of a continuous monitoring activity, and of reliable records of several comparable set of data. Even if some difficulties were encountered in continuous data recording system and in interpretation of validated date, it seem important to continue this kind of monitoring to get a better understanding of crown condition response in relation to several and multiple stress factors and to produce an increase in the knowledge on forest ecosystem.

\section{REFERENCES}

AA. VV. 1991a. Rapporto sullo stato sanitario delle foreste. Provincia Autonoma di Trento, Servizio Foreste Caccia e Pesca: $55 \mathrm{pp}$.

AA. VV. 1991b. Indagine conoscitiva sullo stato sanitario delle foreste in Provincia di Trento. Provincia Autonoma di Trento, Servizio Foreste Caccia e Pesca: 245 pp.

AA. VV. 1992. Monitoring of forest condition in South Tyrol: annual report. Autonomous Province of Bolzano-Bozen, Forestry Inspectorate Bolzano-Bozen: $70 \mathrm{pp}$.

Allavena, S., B. Petriccione \& E. Pompei. 2000. The CONECOFOR programme. In: Ferretti M. (Ed.), Integrated and Combined (I\&C) evaluation of intensive Monitoring of forest Ecosystems in Italy - Concepts, Methods and First Results. Annali Istituto Sperimentale per la Selvicoltura, Special Issue, Arezzo, anno 1999, vol. 30: 17-31.

Ambrosi, P. \& S. Minerbi. 2001. Nuovi approcci nella gestione delle problematiche sanitarie dei boschi alpini. Special number of Annali dell'Accademia Italiana di Scienze Forestali, XLIX: 15-22.

Ambrosi, P., F. Bertolini, E. George, S. Minerbi, \& C. Salvadori. 1997. Integrated monitoring in alpine forest ecosystems in Trentino and South Tyrol, Italy. Chemosphere, 36: 1043-1048.

AOAC International-J. 1970. 16th ed. of Official Methods of Analysis of AOAC international. 0742, Mc Lean, Virginia USA.

APHA, AWWA, WEF. 1992. Standard methods for the examination of water and wastewater. Am. Publ. Health Ass., 18th ed.

Bernetti, G. 1995. Selvicoltura speciale. UTET, Torino: 415 $\mathrm{pp}$.

Biino, U. \& C. Tazzi. 1998. Analisi nutrizionale delle foglie. In: A. Ballarin Denti, S. M. Cocucci, F. Sartori (Eds), Monitoraggio delle foreste sotto stress ambientale. Fondazione Lombardia per l'Ambiente: 173-179.

Bonanni, P., S. Brini, G. Delmonaco, R. Liburdi, A. Troccola \& G. Vetrella. 1998. Mappa dei carichi critici di acidità totale riferita al territorio italiano. Rapporto ENEA. Centro Ricerche Casaccia, Roma: 60 pp.

Bussotti, F. \& M. Ferretti. 1998. Air pollution, forest condition and forest decline in Southern Europe: an overview. Environ. Pollut. 101: 49-65.

De Vries, W., J. M Klap \& W. Erisman. 2000. Effects of environmental stress on forest crown condition in Europe. Part 1: Hypotheses and approach to the study. Water Air and Soil Pollution, 119: 317-333.

Doytchinov, S. 1996. Inquinamento a lunga distanza: un problema europeo. In: Deposizioni atmosferiche totali ed ecosistemi forestali. Lo stato della ricerca nell'areale alpino. Cimolais (Pordenone - I.) 6-7 nov. 1996: 125-136.

Eccel, E. \& G. Toller. 1996. Annale meteorologico e climatologico della rete automatica SPARTAC. Iasma edizioni: $184 \mathrm{pp}$.

ICP-IM Programme Centre. 1998. International Cooperative Programme on Integrated Monitoring of Air Pollution Effects on Ecosystems. Manual for Integrate Monitoring. Finnish Environment Institute.

Innes, J. L. 1993. Forest Health: its assessment and Status. CAB International Oxon, UK: $677 \mathrm{pp}$.

Kandler, O. \& J.L. Innes. 1995. Air pollution and forest decline in central Europe. Environ. Pollut., 90: 171-180.

La Porta, N., C. Salvadori \& P. Ambrosi. 2001. Monitoraggio micologico per la valutazione della biodiversità in due località forestali della provincia di Trento. Atti del 5 Convegno nazionale sulla Biodiversità. Caserta, Belvedere di S. Leucio 9-10 settembre 1999: 420-427.

Marchetti, F., D. Tait, P. Ambrosi \& S. Minerbi. 2002. Atmospheric deposition at four forestry sites in the Alpine Region of Trentino-South Tyrol, Italy. In: Mosello, R., B. Petriccione \& A. Marchetto (Eds), Long-term ecological research in Italian forest ecosystems. J. Limnol., 61 (Suppl. 1): 148-157.

Maresi, G., P. Ambrosi, M. Confalonieri \& P. Capretti. 1999. Disseccamenti da Cenangium ferruginosum e Sphaeropsis sapinea nelle pinete trentine. Monti e Boschi, L, 2: 35-41.

Michaelis, W., 1997. Air Pollution. Dimensions, Trends and Interactions with a Forest Ecosystem. Springer Ver. Berlin-Heidelberg: 175+VI pp.

Minerbi, S., P. Ambrosi \& F.Bertolini. 1996. Programma di monitoraggio integrato in ecosistemi forestali nella provincia di Bolzano e di Trento. Primi risultati. Monti e Boschi, XLVII, 2: 26-34.

Schleppi, P., L. Tobler, J.B. Bucher \& A. Wyttenbach. 2000. Multivariate interpretation of the foliar chemical composi- 
tion of Norway spruce (Picea abies). Plant and Soil, 219: 251-262.

Schröter, H. \& E. Aldinger. 1985. Beurteilung des gesundheitszustandes von Fichte und Tanne nach der Benadelungsdichte. Allgemeine Forstzeischrift, Munchen, n. 18.

Tait, D \& B. Thaler. 2000. Atmospheric deposition and lake chemistry trends at high mountain site in the eastern Alps. J. Limnol., 59 (1): 61-71.

Van Leeuwen, E. P., K. C. M. A. Hendriks, J. M Klap, W. De Vries, E. De Jong \& W. Erisman. 2000. Effects of envi- ronmental stress on forest crown condition in Europe. Part II: Estimation of stress induced by meteorology and air pollutants. Water, Air and Soil Pollution, 119: 335-362.

WMO, 1998. The global climate system review. Dec. 1993May 1996. WMO No. 856. Geneva (CH).

Zanon, G. 1999. 1996-1997: le variazioni dei ghiacciai italiani. La Rivista del Club Alpino Italiano, maggiogiugno: 75-78. 